\title{
Triploid and Aneuploid Hybrids from Diploid-diploid Intergeneric Crosses between Citrus Cultivar 'Kiyomi' Tangor and Meiwa Kumquat (Fortunella crassifolia Swingle) for Seedless Breeding of Kumquats
}

\author{
Kiichi Yasuda $^{1}$, Masaki Yahata ${ }^{2}$, Haruki Komatsu $^{3}$, Yoshikazu Kurogi ${ }^{4}$ and Hisato Kunitake ${ }^{5 *}$ \\ ${ }^{1}$ The Interdisciplinary Graduate School of Agriculture and Engineering, University of Miyazaki, Miyazaki 889-2192, Japan \\ ${ }^{2}$ The Faculty of Agriculture, Shizuoka University, Shizuoka 422-8529, Japan \\ ${ }^{3}$ School of Agriculture, Tokai University, Kumamoto 869-1404, Japan \\ ${ }^{4}$ Ecological Agriculture Division, Field Science Center, University of Miyazaki, Miyazaki 889-2192, Japan \\ ${ }^{5}$ Faculty of Agriculture, University of Miyazaki, Miyazaki 889-2192, Japan
}

\begin{abstract}
In order to produce new seedless kumquat cultivars, we carried out an intergeneric cross between 'Kiyomi' tangor [Citrus unshiu Marcow. $\times$ C. sinensis (L.) Osbeck] and Meiwa kumquat (Fortunella crassifolia Swingle), obtaining 2 normal seeds and 7 undeveloped seeds. These seeds were cultivated on Murashige and Tucker medium, and the 2 normal seeds germinated and developed. The results of genome size analysis by flow cytometry revealed that both seedlings were triploids and that the difference in genome size corresponded to more than one chromosome in the 2 seedlings. Chromosome observation confirmed diploid $(2 n=2 x=18)$ in both parents, aneuploid with 28 chromosomes $(2 n=28)$ for one of the seedlings, and triploid $(2 n=3 x=27)$ for the other seedling. Random amplified polymorphic DNA (RAPD) and cleaved amplified polymorphic sequence (CAPS) analyses proved that the seedlings were intergeneric hybrids between 'Kiyomi' tangor and Meiwa kumquat, with the maternal organelle genome. These hybrids have the potential to be released as a cultivar after further tree and fruit evaluations, and for use as cross-parents in seedless kumquat breeding.
\end{abstract}

Key Words: aneuploidy, flow cytometry, genome size analysis, 'Kiyomi’ tangor, Meiwa kumquat.

\section{Introduction}

The kumquat (Fortunella) is closely related to Citrus and Poncirus in the subfamily Aurantioideae (Citroideae) of the family Rutaceae (Swingle and Reece, 1967). Species in this genus are important as genetic resources for Citrus breeding because they have cold hardiness, pest tolerance, small tree size, and small fruit with an edible peel. They have been cultivated for both as table fruit and for processing in mainly Japan, China, and Peninsular Malaysia. In Japan, the most cultivated kumquat is the Meiwa kumquat (F. crassifolia Swingle), which has the best eating quality in this genus; it has also been used widely for candied fruits, jam, marmalade, and fruit wine in addition to table use.

So far, only 4 kumquat varieties have been registered under the Plant Variety Protection and Seed Act in

Received; February 7, 2009. Accepted; July 24, 2009.

This research was supported by KAKENHI (No. 20580034).

* Corresponding author (E-mail: hkuni@cc.miyazaki-u.ac.jp).
Japan (Ministry of Agriculture, Forestry and Fisheries, http//www.hinsyu.maff.go.jp, April 26, 2009): 'Konta' (registration no. 10249), 'Yumichan-no-hoppe' (registration no. 14785), 'Yubeni' (registration no. 14416), and 'Puchimaru' (registration no. 10379).

'Yubeni' is a ploidy periclinal chimera derived from bud mutation in the Meiwa kumquat (Yasuda et al., 2008). 'Puchimaru' is an interspecific hybrid derived from a cross between an oval kumquat $[F$. margarita (Lour.) Swingle] and an autotetraploid Meiwa kumquat (Kawase et al., 2005; Yoshida et al., 2003). 'Konta' sets fruits with an extremely low acidity, 'Yumichan-nohoppe' is an early maturing cultivar, and 'Yubeni' has large fruits with a small number of seeds caused by ploidy periclinal chimera. 'Puchimaru' is a triploid cultivar produced for the purpose of breeding seedless cultivars, but the cultivar is not completely seedless because the fruits often contain a few seeds and/or undeveloped seeds (Yoshida et al., 2003). Although seedlessness is a highly desirable trait in the breeding of kumquats, no seedless kumquat cultivar has yet been 
produced.

'Kiyomi' tangor [C. unshiu Marcow. $\times$ C. sinensis (L.) Osbeck] is a superior citrus cultivar with undeveloped anthers caused by cytoplasmic-genic male sterility and strong parthenocarpy which are very important traits for the production of seedless fruits (Nakano et al., 2001; Nishiura et al., 1983; Yamamoto et al., 1997). Moreover, the cultivar has seed monoembryony, which make it suitable for breeding as a seed parent. To date, a great number of high quality cultivars with male sterility and parthenocarpy for seedlessness, such as 'Tsunokaori' and 'Shiranui', have been produced from crosses with 'Kiyomi' tangor as the seed parent (Yoshida, 2003). Therefore, we proposed the production of intergeneric hybrids between 'Kiyomi' tangor as a seed parent and kumquats, as a new breeding method for seedless kumquat cultivars.

There is a high intergeneric cross compatibility between Citrus and Fortunella. Intergeneric hybrids such as limequats [Citrus aurantifolia (Cristm.) Swingle $\times$ Fortunella sp.] are documented to have arisen as chance seedlings (Swingle and Reece, 1967). Furthermore, Iwamasa et al. (1988) successfully produced hybrids between the oval kumquat and the sour orange (C. aurantium L.) in a study on cross compatibility among Aurantioideae. In the present study, we attempted crosses between 'Kiyomi' tangor and 6 Fortunella species, and performed ploidy and hybridity analyses by flow cytometry analysis, chromosome observation, random amplified polymorphic DNA (RAPD) analysis and cleaved amplified polymorphic sequence (CAPS) analysis for cytoplasmic DNA. We report here that triploid and aneuploid hybrids were obtained from diploid-diploid intergeneric crosses between 'Kiyomi' tangor and Meiwa kumquat.

\section{Materials and Methods}

\section{Plant materials}

For crossing in the present study, we used 'Kiyomi' tangor as a seed parent and the 6 Fortunella species established by Tanaka (1933) were used as pollen parents: the oval kumquat, round kumquat [F.japonica (Thunb.) Swingle], Meiwa kumquat, Malayan kumquat [F.polyandra (Ridl.) Tanaka], Changshou kumquat (F. obovata hort. ex Tanaka), and Hongkong kumquat [F. hindsii (Champ. ex Benth.) Swingle var. chintou]. The 'Kiyomi' tangor used in this study was conserved at the Kumamoto Prefectural Agricultural Research Center in Japan. Pollens were collected from the flowers of the 6 Fortunella species maintained in a greenhouse at Tokai University, Kumamoto, Japan.

\section{Intergeneric crosses}

The cross combinations are shown in Table 1 . The pollens of the 6 Fortunella species were collected and stored at $-40^{\circ} \mathrm{C}$ for one year until crossing, because the flowering period varies widely between Citrus (May) and Fortunella (July to August). Pollen fertility was evaluated by percent pollen germination on $1 \%$ agar medium containing $10 \%$ sucrose. The randomly-selected anthers were rubbed on the agar medium, and the slides were then incubated for $10 \mathrm{~h}$ in a moistened chamber at $25^{\circ} \mathrm{C}$ in the dark. Three hundred pollen grains were observed per slide, and the percent pollen germination was determined on three slides for each sample. The flowers were pollinated immediately after emasculation and covered with paraffin paper bags. Seeds were collected from the fruits of all crosses at maturity and were classified into three groups (normal, small, and undeveloped) based on their size and shape. Small and undeveloped seeds were defined as seed $1 / 2$ to $1 / 6$ the size of normal seeds and empty seeds, respectively. Developed seeds included both normal and small seeds. Both developed and undeveloped seeds were then cultured on Murashige and Tucker (MT) medium (Murashige and Tucker, 1969) containing $500 \mathrm{mg} \cdot \mathrm{L}^{-1}$ malt extract, $30 \mathrm{~g} \cdot \mathrm{L}^{-1}$ sucrose, and $2 \mathrm{mg} \cdot \mathrm{L}^{-1}$ gellan gum at $25^{\circ} \mathrm{C}$ under continuous illumination $\left(38 \mu \mathrm{mol} \cdot \mathrm{m}^{-2} \cdot \mathrm{s}^{-1}\right)$. After germination, the 2 seedlings obtained from the cross were transplanted to vermiculite in pots and were

Table 1. Fruit set, seed contents, and number of seedlings in the crosses between 'Kiyomi' tangor and the 6 Fortunella.

\begin{tabular}{|c|c|c|c|c|c|c|c|c|c|c|c|}
\hline \multicolumn{2}{|c|}{ Cross combination } & \multirow{2}{*}{$\begin{array}{c}\text { No. of } \\
\text { flowers } \\
\text { pollinated }\end{array}$} & \multirow{2}{*}{$\begin{array}{l}\text { No. of } \\
\text { fruits set }\end{array}$} & \multirow{2}{*}{$\begin{array}{l}\% \text { of } \\
\text { fruits set }\end{array}$} & \multirow{2}{*}{$\begin{array}{l}\text { Av. fruit } \\
\text { wt. (g) }\end{array}$} & \multicolumn{3}{|c|}{ No. of seeds } & \multirow{2}{*}{$\begin{array}{c}\text { No. of } \\
\text { developed } \\
\text { seeds per } \\
\text { fruit }^{\mathrm{w}}\end{array}$} & \multirow{2}{*}{$\begin{array}{c}\% \text { of } \\
\text { germinated } \\
\text { seeds }^{v}\end{array}$} & \multirow{2}{*}{$\begin{array}{l}\text { No. of } \\
\text { seedlings }\end{array}$} \\
\hline Seed parent & Pollen parent ${ }^{z}$ & & & & & Normal & Smally $^{y}$ & Undeveloped $^{\mathrm{x}}$ & & & \\
\hline \multirow{7}{*}{ 'Kiyomi' tangor } & Open pollination & - & 10 & - & 371.6 & 70 & 0 & 24 & 7.0 & - & - \\
\hline & Oval kumquat & 30 & 7 & 23.3 & 262.9 & 2 & 0 & 0 & 0.3 & 100 & 2 \\
\hline & Round kumquat & 20 & 5 & 25.0 & 384.2 & 0 & 0 & 0 & 0 & - & - \\
\hline & Meiwa kumquat & 20 & 5 & 25.0 & 370.8 & 2 & 0 & 7 & 0.4 & 100 & 2 \\
\hline & Malayan kumquat & 22 & 6 & 27.3 & 358.2 & 76 & 0 & 11 & 13.0 & 93.4 & 64 \\
\hline & Changshou kumquat & 19 & 3 & 15.8 & 334.7 & 12 & 0 & 0 & 4.0 & 83.3 & 8 \\
\hline & Hongkong kumquat & 20 & 8 & 40.0 & 329.0 & 0 & 0 & 0 & 0 & - & - \\
\hline
\end{tabular}

\footnotetext{
Malayan, Changshou, and Hongkong kumquats, respectively (storage at $-40^{\circ} \mathrm{C}$ for one year).

y $1 / 2$ to $1 / 6$ the size of normal seeds.

${ }^{x}$ Empty seeds.

${ }^{\mathrm{w}}$ Developed seeds included both normal and small seeds

v $\%$ of germinated seeds $=($ No. of seedlings $/$ No. of developed seeds $) \times 100$.
}

$\mathrm{z}$ The pollen germination percentages on $1 \%$ agar medium contained $10 \%$ sucrose were $12.9,1.2,19.0,5.2,13.2$, and $2.0 \%$ in oval, round, Meiwa, 
transferred to a greenhouse, where they were grafted onto trifoliate orange [Poncirus trifoliata (L.) Raf.] and cultivated at the Kibana Agriculture Science Station of the University of Miyazaki, Japan.

\section{Genome size analysis}

Completely mature leaf segments of approximately $1 \mathrm{~cm}^{2}$ were collected from each of the seedlings and their parents, and chopped with a razor blade. These samples were treated for $5 \mathrm{~min}$ in $1 \mathrm{~mL}$ buffer solution containing $1.0 \%$ (v/v) Triton X-100 (Nacalai Tesque, Inc., Kyoto, Japan), $140 \mathrm{mM}$ mercaptoethanol, $50 \mathrm{mM} \mathrm{Na}_{2} \mathrm{SO}_{3}$ and $50 \mathrm{mM}$ Tris- $\mathrm{HCl}$ at $\mathrm{pH} 7.5$, prior to preparation following the method described by Yahata et al. (2005). Crude samples were filtered at $550 \mu \mathrm{L}$ through Miracloth (Merck KGaA, Darmstadt, Germany) and stained with $25 \mu \mathrm{g} \cdot \mathrm{L}^{-1}$ propidium iodide (PI) (Nacalai Tesque). The relative fluorescence of the total DNA was measured for each nucleus using a flow cytometry system (EPICS XL; Beckman Coulter, Inc., Fullerton, CA, USA) equipped with an argon laser $(488 \mathrm{~nm}, 15 \mathrm{~mW})$. To calculate the relative nuclear DNA content of the obtained seedlings, the nuclei of a haploid pummelo [C. maxima (Burm.) Merr.; $2 \mathrm{n}=\mathrm{x}=9$ ] were used as an internal standard (Toolapong et al., 1996). A reliable value for the haploid pummelo (391 Mbp/2C) was determined by comparison with Tahiti lime (C. aurantifolia Swing.; $1.17 \mathrm{pg} / 2 \mathrm{C}, 2 \mathrm{n}$ $=3 \mathrm{x}=27$ ) using 30 samples (Ollitrault et al., 1994). The relative nuclear DNA content of each sample was estimated using the following formula: [(sample $\mathrm{G}_{1}$ peak position)/(standard peak position)] $\times$ standard DNA content $(\mathrm{pg} / 2 \mathrm{C})$, and was measured three times for statistical analysis (Tukey's multiple range test). These data were then converted to the putative nuclear genome size at $\left(0.978 \times 10^{9}\right)$ bp to $1 \mathrm{pg}$ (Dolezel et al., 2003).

\section{Chromosome observation}

Young leaves (approximately 3-5 mm long) were excised from 'Kiyomi' tangor, Meiwa kumquat and the seedlings, immersed in $2 \mathrm{mM}$ 8-hydroxyquinoline for $10 \mathrm{~h}$ at $4^{\circ} \mathrm{C}$, and fixed in a mixed solution of ethanol and acetic acid $(3: 1)$ for $12 \mathrm{~h}$ at $4^{\circ} \mathrm{C}$. Enzymatic maceration and air-drying were performed following the method described by Fukui (1996) with some modifications. The young leaves were washed in distilled water to remove the fixative and then macerated in an enzyme mixture containing 2.0\% (w/v) Cellulase Onozuka RS (Yakult Pharmaceutical Ind. Co., Ltd., Tokyo, Japan), $1.0 \%(\mathrm{w} / \mathrm{v})$ Macerozyme (MP Biomedicals, Inc., Irvine, CA, USA), $0.3 \%$ Pectolyase Y-23 (w/v) (Kyowa Chemical Products Co., Ltd., Osaka, Japan) and $200 \mathrm{mM}$ ethylenediaminetetraacetic acid (EDTA) at $37^{\circ} \mathrm{C}$ for $40 \mathrm{~min}$. The chromosomes were stained with $2.0 \%$ Giemsa solution (Merck) in $1 / 30 \mathrm{M}$ phosphate buffer (pH 6.8) for $30 \mathrm{~min}$. They were then rinsed with distilled water, air dried, and observed under an optical microscope. After confirming the position on the slide, the chromosomes were de-stained with 70\% methanol, re-stained with $0.1 \mathrm{mg} \cdot \mathrm{L}^{-1}$ propidium iodide (Nacalai Tesque) and observed under a fluorescence microscope (Olympus Co., Ltd., Tokyo, Japan) with a green (G) filter cassette.

\section{Molecular marker analyses}

Total DNA was extracted from young leaves of each plant following the method described by Doyle and Doyle (1987). The total DNA was used for RAPD and CAPS analyses.

RAPD analysis of nuclear DNA was performed by a modified version of the methods described by Williams et al. (1990). Polymerase chain reaction (PCR) was carried out with Operon random 10-mer primers (Operon Technologies Inc., Alameda, CA, USA) using the Astec Program Control System PC-700 (Astec Co., Ltd., Fukuoka, Japan). The reaction products were electrophoresed on $1.5 \%$ agarose gels containing $25 \mu \mathrm{l} \cdot \mathrm{L}^{-1}$ SYBR Safe ${ }^{\mathrm{TM}}$ (Life Technologies Japan Ltd., Tokyo, Japan) and subsequently photographed under ultraviolet light $(360 \mathrm{~nm})$. For each combination of sample and primers, PCR was carried out twice, and only stable polymorphisms were analyzed.

CAPS analysis was performed for several chloroplastic (cp) and mitochondrial $(\mathrm{mt})$ non-coding regions. For cpDNA analysis, three primer pairs of trnK-3914F-trnK$2 R, r b c L-p s a I$, and $t r n D$-trnT were used for amplification following the methods of Cheng et al. (2002) and Ureshino and Miyajima (2002). For mtDNA analysis, five primer pairs of $18 S r R N A-5 S r R N A$, nad4exon1nad4exon2, nad5/1-nad5/2r, nad7/1-nad7/2r, and nad1/4-nad1/5r were used for amplification following the methods of Cheng et al. (2002) and DumolinLapegue et al. (1997). The PCR products were digested with several restriction endonucleases and then electrophoresed under the same protocol as that used in our RAPD analysis.

\section{Results and Discussion}

We made crosses between 'Kiyomi' tangor and the 6 Fortunella species (Table 1). All pollens stored at $-40^{\circ} \mathrm{C}$ for one year had maintained sufficient fertility for crossing (Data shown in the footnote for Table 1). Of the 6 cross combinations, seeds were successfully obtained from the crosses with the oval, Meiwa, Malayan and Changshou kumquats.

The numbers of seeds obtained from the crosses with the Malayan kumquat and the Changshou kumquat were larger than those obtained from the other cross combinations. The Malayan and Chanshou kumquats are presumed to be intergeneric hybrids of Citrus with Fortunella (Swingle and Reece, 1967). The relatively large number of seeds obtained from the crosses with these species in the present study might be explained by this assumption.

No seeds were obtained from the crosses with the 
round or Hongkong kumquats. Both of these kumquats showed lower pollen germination percentages $(1.2 \%$ for the round kumquat, $2.0 \%$ for the Hongkong kumquat) on $1 \%$ agar medium containing $10 \%$ sucrose than the other species, which may have caused the failure to hybridize. In addition, the Hongkong kumquat belongs to Protocitrus, which does not include the other 5 species (Swingle and Reece, 1967; Tanaka, 1933); this might have caused stronger reproductive isolation with Citrus.

When the Meiwa kumquat was used as a pollen parent, 2 normal seeds and 7 undeveloped seeds were obtained. All of these seeds were cultured on MT medium. Only the 2 normal seeds germinated normally, but the seedlings (identified as H15-701 and H15-702) then showed poor growth in vitro (Fig. 1A, 1B). However, they recovered and grew vigorously during the early stage after being transplanted to soil (Fig. 1C). At the same time, 2, 64, and 8 seedlings were obtained from the crosses with the oval, Malayan, and Changshou kumquats, respectively. Ploidy analyses and confirmation of hybridism are presently being carried out on these seedlings (data not shown). In the present study, we focused on H15-701 and H15-702 obtained from the cross between 'Kiyomi' tangor and the Meiwa kumquat.

H15-701 and H15-702 were analyzed for ploidy levels by flow cytometry analysis. In this analysis, both parents showed diploidy peaks, while both seedlings showed unexpected triploidy peaks (Fig. 2). Furthermore, the putative genome sizes of each sample were also obtained from the relative nuclear DNA content using flow cytometry. The putative genome sizes of H15-701, H15702 , and their parents were investigated using the haploid pummelo as an internal standard (Fig. 3). The putative genome sizes of 'Kiyomi' tangor and the Meiwa kumquat were $781 \mathrm{Mbp} / 2 \mathrm{C}$ and $774 \mathrm{Mbp} / 2 \mathrm{C}$, respectively, while those of H15-701 and H15-702 were $1234 \mathrm{Mbp} / 2 \mathrm{C}$ and $1164 \mathrm{Mbp} / 2 \mathrm{C}$, respectively. Interestingly, the significant difference in genome size corresponded to more than one chromosome represented in the 2 seedlings, suggesting the possibility of an aneuploid.

The chromosome count of young leaves in 'Kiyomi' tangor and the Meiwa kumquat used as cross parents confirmed eudiploidy $(2 \mathrm{n}=2 \mathrm{x}=18$; Fig. 4A, 4B). Chromosome observation also revealed that H15-701 and H15-702 were an aneutriploid $(2 \mathrm{n}=28)$ and a eutriploid $(2 n=3 x=27)$, respectively (Fig. 4C, 4D). Flow cytometry analysis has been used to screen for aneuploidy in several plant species. The addition of a larger number of chromosomes can be determined based on differences in peak positions (Kopecky and Vagera,
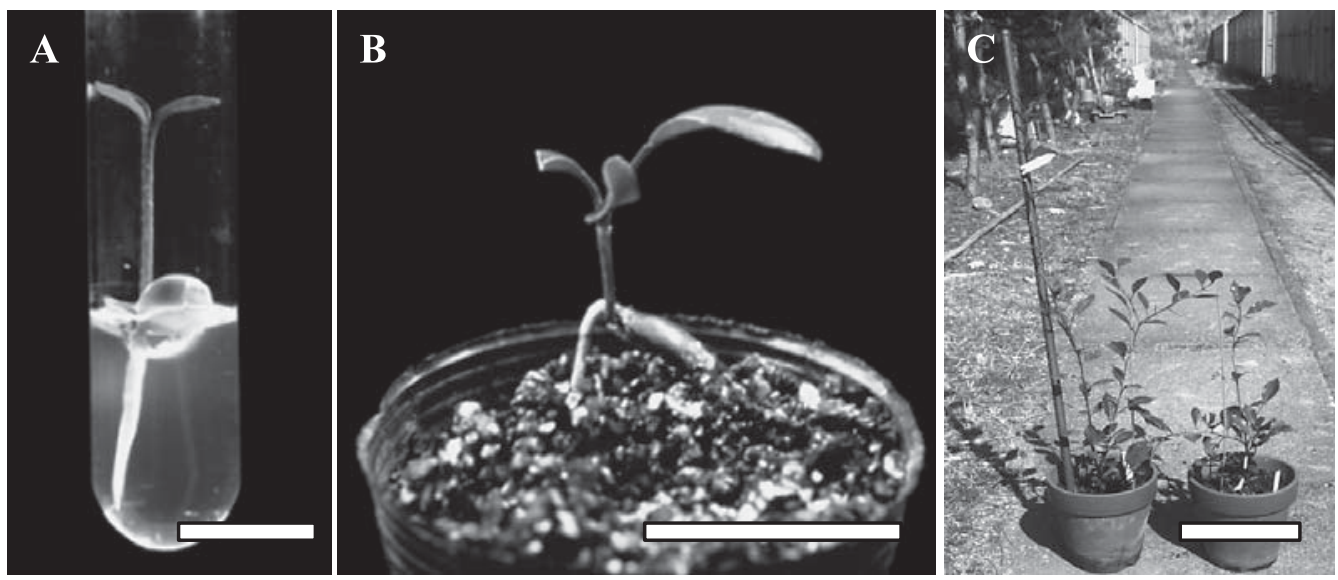

Fig. 1. Photographs of the 2 seedlings obtained from a cross between 'Kiyomi' tangor and the Meiwa kumquat. A: a seedling germinated in vitro $(\mathrm{Bar}=1.5 \mathrm{~cm})$, B: a seedling soon after acclimatization $(\mathrm{Bar}=3.0 \mathrm{~cm}), \mathrm{C}$ : growth and development of the seedlings during the early stage $(\mathrm{Bar}=30 \mathrm{~cm})$.

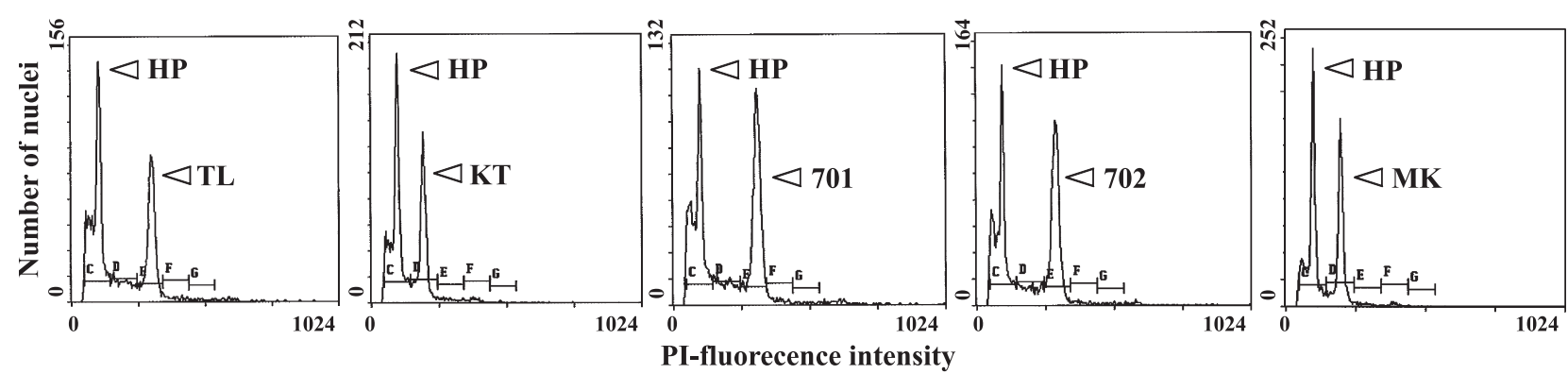

Fig. 2. Histograms of the flow cytometry analysis of mature leaves of 'Kiyomi' tangor, the Meiwa kumquat, and the 2 seedlings obtained from the cross. The haploid pummelo was used as an internal standard. HP: haploid pummelo, TL: Tahiti lime, KT: 'Kiyomi' tangor, 701: H15701, 702: H15-702, MK: Meiwa kumquat. 


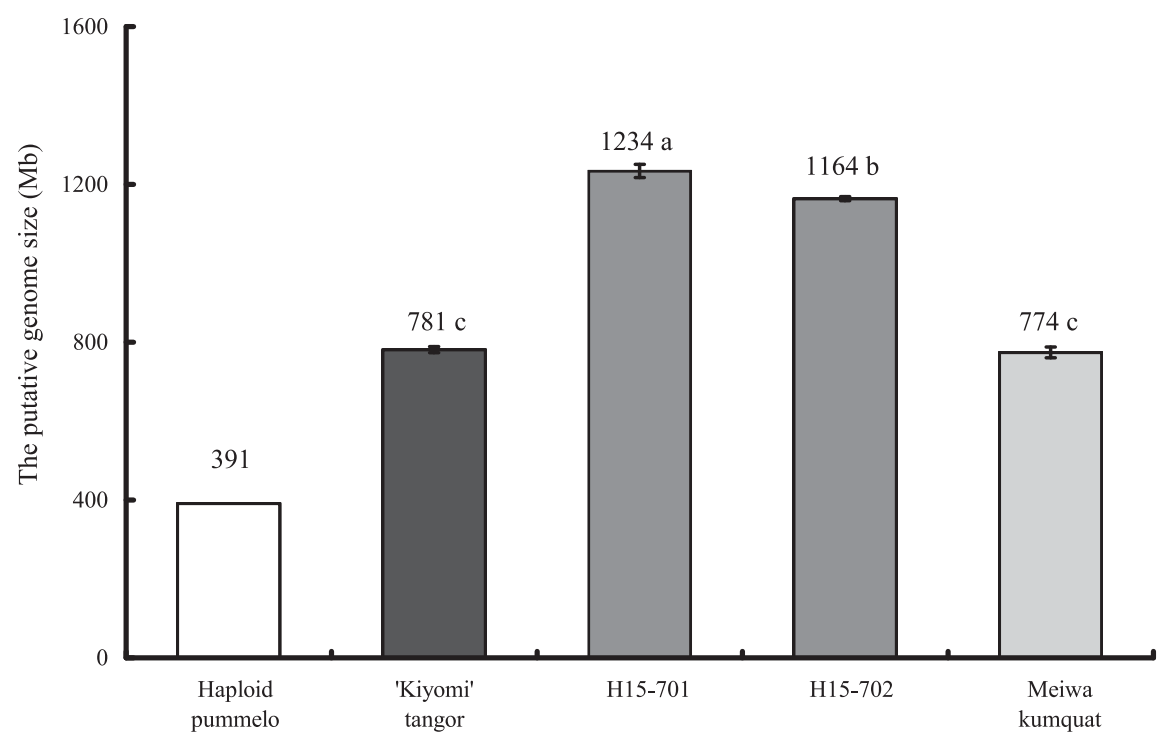

Fig. 3. The putative genome size of 'Kiyomi' tangor, the Meiwa kumquat, and the 2 seedlings, H15-701 and H15-702, obtained from the cross determined by comparison with the haploid pummelo as an internal standard. Different letters represent significant differences in Tukey's multiple range test, $1 \%$ level $(\mathrm{n}=5)$. The nuclear genome size of the haploid pummelo was determined by comparison with the Tahiti lime $(\mathrm{n}=30)$.
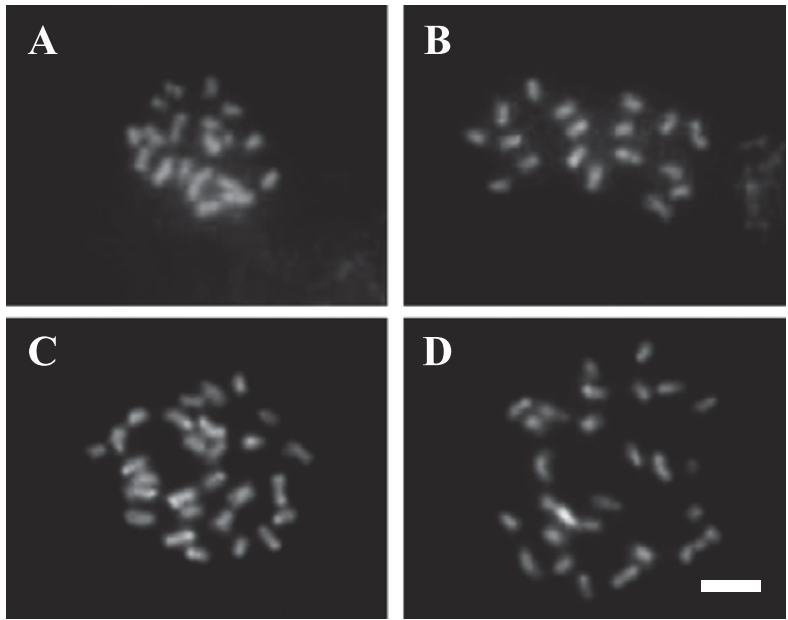

Fig. 4. Somatic chromosomes at metaphase in young leaves of 'Kiyomi' tangor, the Meiwa kumquat, and the 2 seedlings obtained from the cross. A: 'Kiyomi' tangor $(2 n=2 x=18)$, B: Meiwa kumquat $(2 \mathrm{n}=2 \mathrm{x}=18)$, C: H15-701 $(2 \mathrm{n}=28)$, D: H15$702(2 \mathrm{n}=3 \mathrm{x}=27)$. The bar in D represents $5.0 \mu \mathrm{m}$ for all figures.

2005; Nakamura et al., 2005). However, it is impossible to determine based solely on differences in peak positions exactly whether a given species has one or two added chromosomes. The results of the genome size analysis in the present study clearly revealed the addition of one chromosome in H15-701, suggesting that genome size analysis may be used effectively to screen for aneuploidy in plants with a small genome size such as citrus.

To confirm the hybridism of these seedlings, we carried out RAPD analysis on the 2 seedlings and both parents. Polymorphism banding patterns were obtained in 8 of 20 random primer pairs used for the experiment. As shown in Figure 5, both seedlings yielded bands specific to both parents, confirming the hybridism of the seedlings.

CAPS analysis for cytoplasmic DNA regions was then performed to examine normal maternal inheritance. While every primer pair amplified the bands satisfactorily, none revealed any polymorphism on the agarose gels. When the PCR products were digested with 4 restriction endonucleases, cpDNA polymorphism was observed in 2 primer/enzyme combinations: rbcL-psaI/ Hinfl and trnD-trnT/MboI (Fig. 6A). MtDNA polymorphism was observed in 3 primer/enzyme combinations: nad7/1-nad7/2r/AluI, 18SrRNA-5SrRNA/HaeIII, and $M b o I$ (Fig. 6B). These seedlings showed uniform bands that were identical to those of the seed parents indicating that their cytoplasmic DNA was of maternal origin.

Thus, RAPD and CAPS analyses confirmed that the seedlings were intergeneric hybrids between 'Kiyomi' tangor (Citrus) and the Meiwa kumquat (Fortunella). The undeveloped anthers of 'Kiyomi' tangor were caused by cytoplasmic-genic male sterility (Yamamoto et al., 1997). If the nuclear genes that regulate male sterility are successfully inherited, the hybrids show undeveloped anthers due to an interaction with the cytoplasmic DNA derived from 'Kiyomi' tangor.

Interestingly, triploid and aneuploid hybrids were obtained from the diploid-diploid cross; however, we were unable to determine whether this phenomenon was selective or nonselective. It has been reported that triploid seedlings were obtained by selecting small seeds from diploid-diploid citrus crosses (Esen and Soost, 1971; Lapin, 1937). On the other hand, aneuploidy occurs with a very low frequency, and most aneuploids never develop to adulthood (Krug and Bacchi, 1943; Sharma and Bal, 1957; Wakana et al., 1981). 


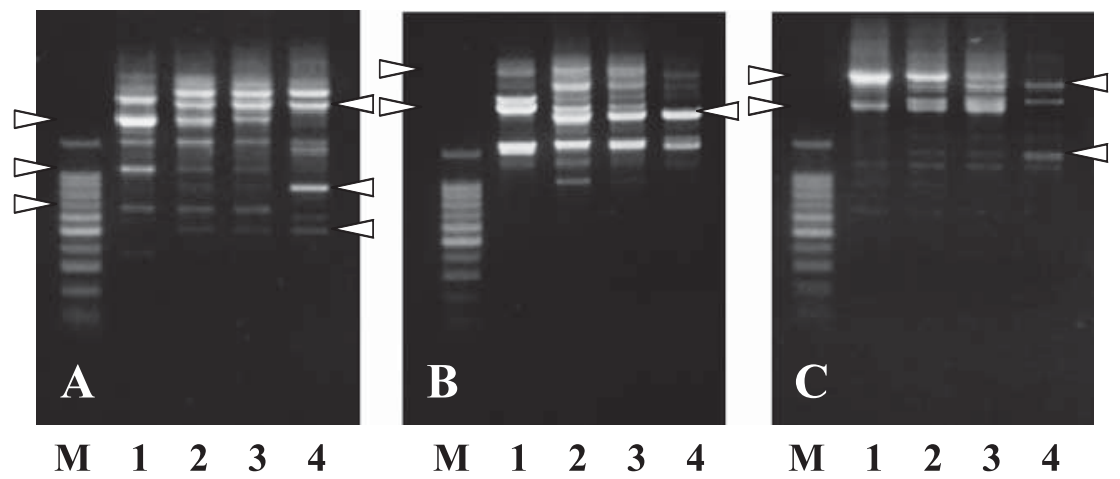

Fig. 5. RAPD analysis of the seedlings obtained from the cross between 'Kiyomi' tangor and the Meiwa kumquat. A: OPA-9 primer, B: OPA12 primer, C: OPA-19 primer. Arrowheads indicate the bands specific to each parent. M: 100-bp ladder marker, 1: 'Kiyomi' tangor, 2: H15-701, 3: H15-702, 4: Meiwa kumquat.

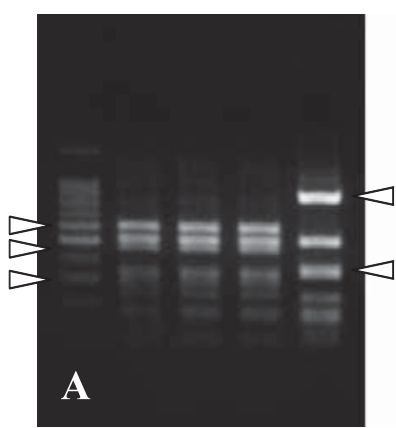

M $11 \quad 2 \quad 3 \quad 3 \quad 4$

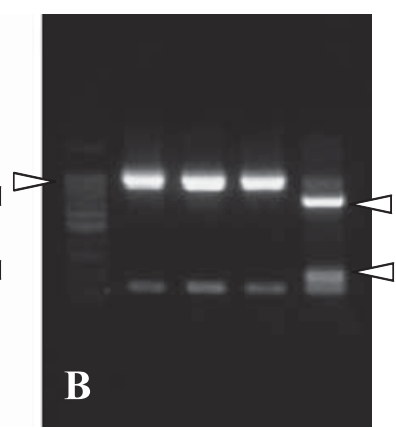

$\begin{array}{lllll}M & 1 & 2 & 3 & 4\end{array}$

Fig. 6. A: restriction pattern of the Hinfl-digested $P S A I-r b c L$ regions of chloroplast genomes. B: restriction pattern of the $A l u \mathrm{I}$-digested nad7/1-nad2r regions of mitochondrial genomes. Arrowheads indicate the bands specific to each parent. M: 100-bp ladder marker, 1: 'Kiyomi' tangor, 2: H15-701, 3: H15-702, 4: Meiwa kumquat.

Aneutriploidy and eutriploidy would also induce the depression of pollen fertility due to meiotic abnormality.

In fact, a large number of fruits including completely seedless fruits set on the present hybrids (Fig. 7), suggesting that they might have extremely low or no pollen fertility and parthenocarpy. The morphological characteristics, male fertility, and fruits traits including sugar and organic acid contents in these fruits are under investigation.

In conclusion, the present cross between 'Kiyomi' tangor and the Meiwa kumquat produced an aneuploid intergeneric hybrid seedling and a eutriploid intergeneric hybrid seedling. These hybrids have the potential for use as cross-parents in seedless kumquat breeding. To determine the genomic constitutions of these hybrids, further investigation is necessary, including Chromomycin A3 (CMA) karyotype analysis, genomic in situ hybridization (GISH) of the somatic chromosomes of these hybrids, and observation of the meiotic chromosome behavior of both parents.
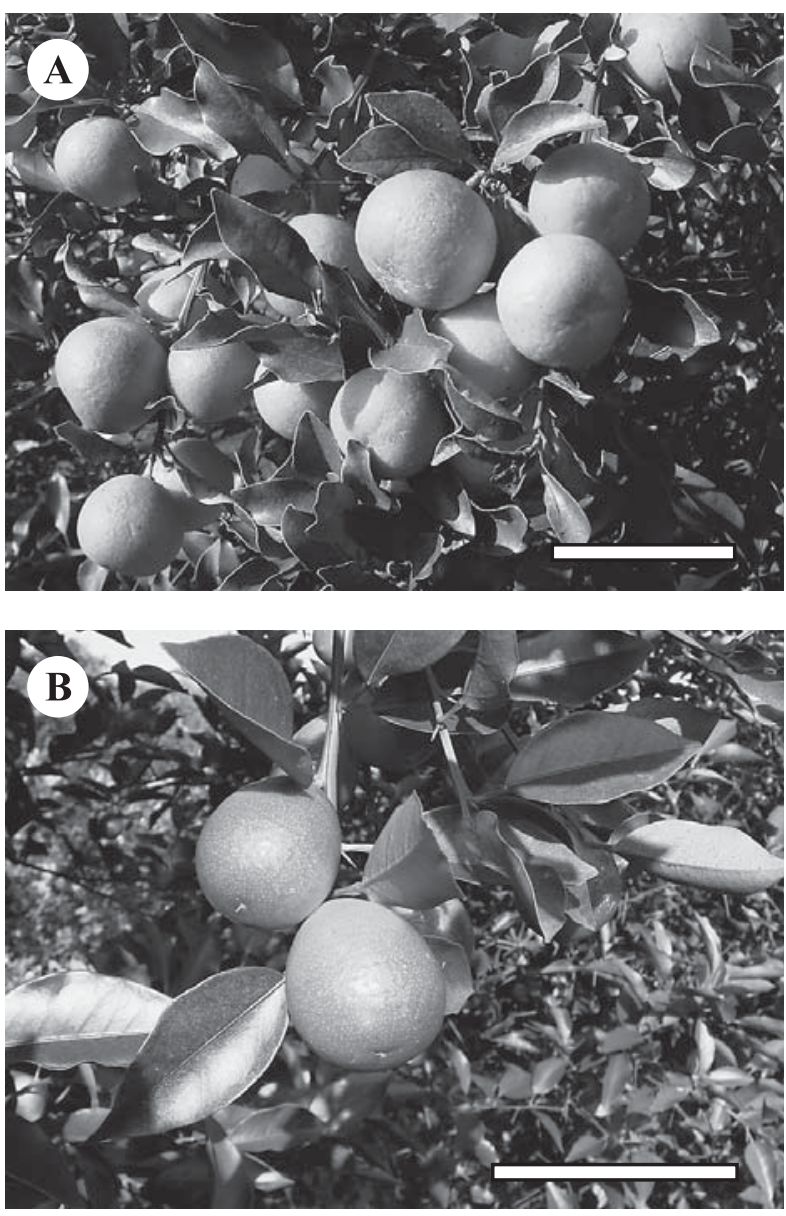

Fig. 7. Photographs of the fruits of the intergeneric hybrids between 'Kiyomi' tangor and the Meiwa kumquat. A: H15-701, B: H15702. $($ Bars $=5.0 \mathrm{~cm})$

\section{Literature Cited}

Cheng, Y. J., W. W. Guo and X. X. Deng. 2002. Inheritance of organelle genomes of the somatic hybrid between Cleopatra mandarin (Citrus reticulata) and Flying dragon (Poncirus trifoliata). Acta Genet. Sin. 29: 364-369.

Dolezel, J., J. Bartos, H. Voglmayr and J. Greilhuber. 2003. Nuclear DNA content and genome size of trout and human. Cytometry Part A 51A: 127-128. 
Doyle, J. and J. L. Doyle. 1987. A rapid DNA isolation procedure for small quantities fresh leaf tissue. Phytochem. Bul. 19: $11-15$.

Dumolin-Lapegue, S., M. H. Pemonge and R. J. Petit. 1997. An enlarged set of consensus primers for the study of organelle DNA in plants. Mol. Ecol. 6: 393-397.

Esen, A. and R. K. Soost. 1971. Unexpected triploids in citrus: their origin, identification and possible use. J. Hered. 62: 329-333.

Fukui, K. 1996. Plant chromosome at mitosis. p. 1-17. In: K. Fukui and S. Nakayama (eds.). Plant chromosome. Laboratry methods. CRC Press, Boca Raton.

Iwamasa, M., N. Nito and J. T. Ling. 1988. Intra- and intergeneric hybridization in the orange subfamily, Aurantioideae. p. 123130. In: R. Goren and K. Mendel (eds.). Proceeding of the International Society of Citriculture, vol 1. Balaband, Rehovot, Israel and Margrat Publishers, Weikersheim.

Kawase, K., M. Yahata, S. Nakagawa, K. Haraguchi and H. Kunitake. 2005. Selection of autotetraploid and its morphological characteristics in Meiwa kumquat (Fortunella crassifolia Swingle). Hort. Res. (Japan) 4: 141-146 (In Japanese with English abstract).

Kopecky, D. and J. Vagera. 2005. The use of mutangens to increase the efficiency of the androgenic progeny production in Solanum nigrum. Biol. Plant. 49: 181-186.

Krug, C. A. and O. Bacchi. 1943. Triploid varieties. J. Hered. 34: 277-283.

Lapin, W. K. 1937. Investigation of polyploidy in citrus. U. S. S. R. All-Union Sci. Res. Inst. Humid Subtropics Works. 1: 1-68.

Murashige, T. and D. P. H. Tucker. 1969. Growth factor requirement of citrus tissue culture. p 1155-1161. In: H. D. Chapmam (ed.). Proceedings of the First International Citrus Symposium, vol 3. University of California, Riverside.

Nakamura, T., S. Kuwayama, S. Tanaka, T. Oomiya, H. Saito and M. Nakano. 2005. Production of intergeneric hybrid plants between Sandersonia aurantiaca and Gloriosa rothschildiana via ovule culture (Colchicaceae). Euphytica 142: 283-289.

Nakano, M., H. Nesumi, T. Yoshioka and T. Yoshida. 2001. Segration of plants with undeveloped anthers among hybrid derived from the seed parent, 'Kiyomi' (Citrus unshiu $\times$ C. sinensis). J. Japan. Soc. Hort. Sci. 70: 539-545.

Nishiura, M., T. Shichijo, I. Ueno, M. Iwamasa, T. Kihara, Y. Yamada, T. Yoshoda and T. Iwasaki. 1983. New citrus cultivar 'Kiyomi' tangor. Bull. Fruit Tree Res. Stn. B (Japan) 10: 1-9 (In Japanese with English abstract).

Ollitraut, P., D. Dambier, F. Luro and C. Duperray. 1994. Nuclear genome size variations in Cirus. Fruits 49: 390-393.

Sharma, A. K. and A. K. Bal. 1957. Chromosome studies in Citrus.
I. Agron. Lusit. 19: 101-126.

Swingle, W. T. and P. C. Reece. 1967. The botany of Citrus and its wild relatives in the orange subfamily. p. 190-430. In: W. Reuther, H. J. Webber and L. D. Bachelor (eds.). The citrus industry, Vol. 1. University of California, Berkeley.

Tanaka, T. 1933. General remarks on the genus Fortunella, (2). Studia Citrologica 6: 19-40.

Toolapong, P., H. Komatsu and M. Iwamasa. 1996. Triploids and haploid progenies derived from small seeds of 'Banpeiyu' pummelo, crossed with 'Ruby Red' grapefruit. J. Japan. Soc. Hort. Sci. 65: 255-260.

Ureshino, K. and I. Miyajima. 2002. The study on the relationship between leaf colors and ptDNA inheritance in intersectional cross of Rhododendron kiusianum $\times R$. japonicum $\mathrm{f}$. flavum, resulting in an unexpected triploid progeny. J. Japan. Soc. Hort. Sci. 71: 214-219.

Wakana, A., M. Iwamasa and S. Uemoto. 1981. Seed development in relation to ploidy of zygotic embryo and endsperm in polyembryonic Citrus. p. 35-39. In: R. Goren and K. Mendel (eds.). Proceeding of the International Society of Citriculture, vol 1. Balaband, Rehovot, Israel and Margrat Publishers, Weikersheim.

Williams, J. G. K., A. R. Kubelik, K. J. Lival, J. A. Rafalski and S. V. Tingey. 1990. DNA polymorphisms amplified by arbitray primers are useful as genetic markers. Nucl. Acids Res. 18: 6531-6535.

Yahata, M., S. Harusaki, H. Komatsu, K. Takami, H. Kunitake, T. Yabuya, K. Yamashita and P. Toolapong. 2005. Morphological characterization and molecular verification of a fertile haploid pummelo (Citrus grandis Osbeck). J. Amer. Soc. Hort. Sci. 130: 34-40.

Yamamoto, M., R. Matsumoto, N. Okudai and Y. Yamada. 1997. Aborted anthers of Citrus result from gene-cytoplasmic male sterility. Sci. Hortic. 70: 9-14.

Yasuda, K., H. Kunitake, S. Nakagawa, H. Kurogi, M. Yahata, R. Hirata, Y. Yoshikura, I. Kawakami and Y. Sugimoto. 2008. The confirmation of ploidy periclinal chimera and its morphological characteristics in Meiwa kumquat 'Yubeni'. Hort. Res. (Japan) 7: 165-171 (In Japanese with English abstract).

Yoshida, T. 2003. Breeding of citrus cultivar 'Kiyomi' with high quality and monoembryony. Breed. Res. (Japan) 5: 103-107 (In Japanese with English abstract).

Yoshida, T., H. Nesumi, T. Yoshioka, H. Ieki, Y. Ito, M. Nakano, I. Ueno, Y. Yamada, S. Murase and F. Takishita. 2003. New kumquat cultivar 'Puchimaru'. Bull. Natl. Inst. Fruit Tree Sci. (Japan) 2: 9-16 (In Japanese with English abstract). 